\title{
The Transfer of Development Rights: Empirical Evidence from Bucks County, Pennsylvania\#
}

\author{
James T. Barrese*
}

The potential misallocation of land has often led to regulations such as zoning. There is, however, a great deal of dissatisfaction with such regulations. Critics claim that at the least zoning regulations have succeeded only in preserving existing neighborhoods and at worst have had little effect on the land uses dictated by strong market forces (Babcock, 1969; Hamilton, 1978; and Ohls, Weisburg and White, 1974). As a result of this dissatisfaction alternative regulations, including a method known as the Transfer of Development Rights (TDR), have been proposed.

TDR plans have been increasingly proposed to offset development pressures which cause the destruction of historical landmarks and environmentally endangered areas (Costonis, 1974, and Rose, 1975). Proponents argue that TDR schemes provide an efficient and equitable method of internalizing the external effects of land development and that TDR schemes utilize market forces to achieve public policy objectives (Rose, 1979). These objectives have included controlling development to protect open spaces, ${ }^{1}$ environmentally endangered areas $^{2}$ and historic landmarks. ${ }^{3}$ Proponents also claim that TDR plans attain these objectives by redirecting aggregate areas growth rather than by reducing growth. This paper provides empirical evidence which does not support this hypothesis of redirected growth.

\section{BACKGROUND}

Within a geographic area TDR plans specify one or more subareas as Preservation Areas (PA). In these preservation areas some definite limits are placed upon future development. For example, a jurisdiction may specify that only current, higher, or lower density uses will be allowed in the future. To be consistent with the majority of TDR plans actually in effect, it will be assumed throughout this paper that a lower density restriction has been applied to the preservation area.

\#The author would like to acknowledge the valuable comments received from Henry Raimondo, Joseph Seneca, Robert Moffit, and James Suarez.

*New York Legislative Tax Study Commission, 6430 Two World Trade Center, New York, NY 10047 
As compensation for the reduction of allowable uses of property within the preservation area. PA owners are given some quantity of Development Rights Certificates (DRCs).

Different subareas are specified as Transfer Areas (TA). If conditions specified in the enabling legislation are met, zoned limits in the transfer area may be exceeded. These conditions require potential developers to purchase some quantity of DRCs if the developer wants to exceed the limit in the TA.

The number of DRCs required to allow development in the TA may vary with the intended location and/or type of development. In this way market incentives can be given to attain various land use objectives.

\section{MODEL AND DATA}

If TDR plans operate in the way hypothesized by TDR proponents, there should be no relationship between the rate of growth of development and a variable indicating the existence of TDR. The growth rate of assessed valuation within an area was chosen as the dependent variable because of the relationship between the development of land and assessment procedures. ${ }^{4}$ If a parcel of land receives a capital improvement, assessed value rises..$^{5}$ If the hypothesis that TDR schemes merely redistribute growth within an area is true there should be either no change or an increase in the rate of growth of assessed value for the area or an increase due to the presumed benefits of the land use controls.

TDR plans exists in two neighboring towns within Bucks County, Pennsylvania, on the northern border of Philadelphia. ${ }^{6}$ The land area of these towns is 9.2 percent of the total county land area. Both plans were instituted in 1974. Data covering the period from 1963 through 1979 were obtained for each of the 54 towns within Bucks County and the following equation estimated. The error components method was used (Balestra and Nerlove, 1966; and Searle, 1971).

RCHAV $_{\text {it }}=b_{0}+b_{1}$ TDR $_{i t}+b_{2}$ DENSITY $_{\text {it }}-b_{3}$ DENSITY $_{\text {it }}-b_{4}$ PLVL $_{\text {it }}$

$$
+b_{5} \text { LPLVL }_{i t}-b_{6} \operatorname{DIST}_{i t}+b_{7} \operatorname{INCOME}_{\mathrm{it}}+e_{\mathrm{it}}
$$

where,

$$
e_{i t}=v_{i}+w_{t}+u_{i t},
$$

and

$\mathrm{RCHAV}_{\mathrm{it}}=$ The rate of change of assessed value in town $\mathrm{i}$, in period t.

$\mathrm{TDR}_{\mathrm{it}}=$ A dummy variable indicating the existence of TDR.

DENSITY $_{\text {it }}=$ The population per square mile.

DENSITY $2_{\mathrm{it}}=$ The square of the ith town's density.

$\mathrm{PLVL}_{\mathrm{it}}=$ The construction price index. 
$\mathrm{LPLVL}_{\mathrm{it}}=$ The lagged value of the construction price index.

DIST $_{\text {it }}=$ The distance of town i from Philadelphia

$\mathrm{INCOME}_{\mathrm{it}}=$ The average per capita money income.

$\mathrm{u}_{\mathrm{it}}=$ The random component of the error.

$v_{i}=$ The cross-sectional component of the error.

$\mathrm{w}_{\mathrm{t}}=$ The time-series component of the error.

The expected relationship between the rate of change of the dependent variable and the construction price index in the current period is negative; that is, the higher the price of construction the lower the rate of new construction. Assessed value is positively related to improvements to property (construction). High construction prices will have a negative effect on construction and, therefore, on the rate of growth of assessed value.

Higher population densities imply a greater demand and higher price for land. However, at some point the population may become extremely concentrated relative to nearby areas. Negative amenities and/or congestion can become sufficiently significant to have an effect upon the demand for and return to ownership in those areas. Area density, therefore, is entered in quadratic form.

Distance is also expected to have a negative effect upon the growth of assessed value. This is the traditional negative rent gradient logic presented by Alonso (1967), Mills (1969, 1970), Muth (1969) and others.

There are two reasons for expecting a positive relationship between income and the rate of growth of assessed value, the quantity of income itself will increase area demand for land and the resulting uses of land will create desirable amenities. Demand for development in these areas will therefore be greater than in lower income areas causing a higher growth rate of assessed value. In addition the type of construction in high income areas is typically of superior quality and is more likely to contain architectural amenities which cause the structure (and perhaps surrounding properties as well) to be assessed at a higher value.

Three variations of the basic model are tested. In the first, distance is dropped from the equation; in the second, distance is added and income is dropped and all variables are included in the third. The primary reason for presenting three models is to note separately the effect which the inclusion of both distance and income have upon the results of the models since multicollinearity problems are often expected for these variables, although in this case correlation coefficient of -0.13 implies that this should not be a problem.

For each of the 54 towns within the county data for the period 1963 through 1979 were obtained. ${ }^{7}$ The range of increase for assessed value was from 12.4 to 274.3 percent with a mean of 39.4 percent and a median value of 44.8 percent. Although the average growth of assessed value for the state was higher than Bucks County's, the distribution of increases within the county is skewed, the median increase within the county is only 5 percent less than the state average.

The range of population change was from 2.6 to 145.4 percent. The mean of 90.2 and median percent change of 62.1 indicate a much greater 
degree of variation for population than was true of assessed value. Finally, average per capita incomes within the county increased much more than did the state average: 100.7 percent for the county with the state increasing by only 54.6 percent. The county's increase was experienced with some degree of uniformity among the towns. The lowest income increase for a Bucks County town was 92.0 percent, with the largest increase within the county 137.7 percent. The median value of 101.5 and mean of 100.7 percent reinforce the impression of uniformity of income increases. These were the basic data which, combined with the area of each town, the distance of each town from Philadelphia, the construction price index, and a dummy variable indicating the existence of TDR schemes, were used to estimate the equations via the error components estimation technique.

\section{METHODOLOGY}

Of the available testing procedures to evaluate TDR's effectiveness, one method is a time series regression employing a Chow test or a dummy variable to test for parameter shifts. These methods, however, have data requirements which could not be met given that applications of TDR schemes have been relatively recent. That is, although Chicago and New York City experimented with the plans in the early seventies, it was the period from 1974 to 1976 which saw their increasing use.

An alternative to the Chow and Dummy variable tests in time series regressions is to use cross sectional data to determine if the growth in the TDR affected area is different from other areas which are similar except for the existence of TDR. The problem in this case is obvious: finding a sufficient number of TDR and non-TDR affected areas which are reasonably similar.

The option which was selected involves the use of the pooling of time series and cross sectional data. One of the advantages of this method is that it increases the number of observations multiplicatively. In this case, 54 towns by 17 years. The time series method would have 17 years for 54 regressions, each with 9 degrees of freedom; the cross sectional method would have 54 towns for 17 regressions. Unfortunately, there are theoretical problem with simple pooling models. The problem of cross sectional comparison remains; that is, finding areas which are reasonably similar. An additional problem is encountered with the use of simple pooling. Such methods are based on the implicit assumption that not only are the cross sections similar today but they have been over time as well. The problem this creates is that if unobserved, unmeasurable, or simply unmeasured factors exist, and are correlated with TDR (in this case), the ordinary least squares estimates will be biased. Justifications for using pooling must include reasons why this assumption of the constancy of effects over time and across, in this case, a geographic area is valid.

One attempt to avoid this problem, if the assumption is valid, is to include dummy variables for time and cross sections. In this way, differences over time and cross sections will be relegated to the intercept term and the effects 


\section{TABLE 1}

Model Estimates

\begin{tabular}{lllll}
\hline \multicolumn{1}{c}{ Variable } & \multicolumn{1}{c}{ Model I } & \multicolumn{1}{c}{ Model II } & \multicolumn{1}{c}{ Model III } & \multicolumn{1}{c}{ OLS } \\
Intercept & -.34648 & .26792 & -.51032 & .78412 \\
& $(-4.0012)$ & $(9.3541)$ & $(-2.4156)$ & $(6.5001)$ \\
TDR & -.24117 & -.17410 & -.23395 & -.09817 \\
& $(-5.6178)$ & $(-4.0929)$ & $(-5.3461)$ & $(-1.9605)$ \\
Density & .09740 & .09093 & .08701 & .00411 \\
& $(1.4565)$ & $(2.0625)$ & $(1.6429)$ & $(.0855)$ \\
Density-squared & -.23461 & -.03000 & -.02479 & .11623 \\
& $(-1.3196)$ & $(-2.6160)$ & $(-2.0483)$ & $(1.4162)$ \\
Price Level & -.00392 & -.00546 & -.00411 & -.15802 \\
& $(-2.4532)$ & $(-12.5520)$ & $(-2.3618)$ & $(-.4339)$ \\
Lagged Price Level & .00229 & .00387 & .00254 & .00729 \\
& $(2.0341)$ & $(14.1920)$ & $(2.5460)$ & $(3.6210)$ \\
Distance & $\mathrm{xxxxx}$ & -.00468 & .00411 & .03067 \\
& $\mathrm{xxxxx}$ & $(-3.6920)$ & $(.2513)$ & $(1.7432)$ \\
Income & .01527 & $\mathrm{xxxxx}$ & .02384 & .14361 \\
& $(6.1540)$ & $\mathrm{xxxxx}$ & $(6.0920)$ & $(9.1508)$ \\
R-square & .9088 & .9426 & .9563 & .7684 \\
\hline
\end{tabular}

of policy variables may be viewed with greater confidence. However, even this method involves implicit assumptions. Unobserved time series influences can be estimated but are implicitly assumed to be the same for all cross sections at a given time. Unobserved cross sectional influences are relegated to the intercept but are assumed to be constant over time. In the present case this would be like saying that the relative influences of the ameities in the 54 towns included in this study is constant over time. If these unobserved factors vary both over time and cross sectionally, the dummy variable technique will also yield biased estimates.

A method of obtaining efficient estimates under uncertainty regarding the validity of these constancy assumptions is known as the error components model. Not only does the error components model allow the estimates to be viewed with greater confidence, the technique also provides an indication of whether a time series, cross sectional, or both variables are missing from the model. In this way, the model may be thought of as a test of the appropriateness of using a pooling model with only time series dummies or cross sectional dummies. The error components method will be explained in greater detail, and with reference to the study of the effect of TDR, below.

\section{EMPIRICAL RESULTS}

The results obtained from the error components method are in general encouraging. With the exception of the third model all estimated coefficients were significant with signs as expected. The results of the three 
models are presented in Table 1; t-statistics are given in parenthesis. Ordinary Least Square results are presented for comparison.

It must be noted that the R-square statistic cannot be interpreted as in the Ordinary Least Squares (OLS) sense (Nerlove, 1971). The predicted estimates of the dependent variable include a portion attributable to the unobserved time-series and cross-sectional variables, not the variables of the model alone. While the loss of this easily interpreted statistic is unfortunate, it is the price of greater confidence in the estimated variable coefficients. The estimated error components for the thiree models are presented in Table 2.

If the estimated error of the time-series component (w) and the crosssection component (v) both equal zero then the error components method is approximately equivalent to OLS. If the ratio of the time-series to the random error $(\mathrm{u})$ estimates is close to one and the cross-sectional estimate is zero then the error components method is equivalent to OLS with crosssectional dummies. If the ratio of the cross-section error to the random error estimates is close to one while the time-series error is zero then the error components method is equivalent to OLS with time-series dummies (Amemiya, 1971).

Since in the above equations none of these conditions hold, the error components method may be the most appropriate estimation technique. OLS regression delegates the influence of all unobserved factors to the error term. The resulting estimates may, therefore, be sensitive to the formal addition of these factors to the model. The error components method on the other hand divides the error into cross-sectional, time-series and random components. The addition of significant factors will now simply reduce either the time-series, cross-sectional or both errors. Thus, the estimates obtained via the error components method may be viewed with greater confidence.

A further positive feature of the error components method is that, by decomposing the total error into its component time-series, cross-sectional and random elements, the percent of the total error accounted for by the various component errors may be calculated. This gives an additional clue as to which, if any, type of variable has been omitted. These figures are also provided in Table 2.

TABLE 2

Estimated Error Components

\begin{tabular}{ccccccc}
\hline & \multicolumn{2}{c}{ Model I } & \multicolumn{2}{c}{ Model II } & \multicolumn{2}{c}{ Model III } \\
Error & Estimate & $\%$ & Estimate & $\%$ & Estimate & $\%$ \\
$\sigma^{2} \mathbf{u}$ & .00146 & 3.38 & .00113 & 2.40 & .00190 & 4.61 \\
$\boldsymbol{\sigma}^{2} \mathrm{w}$ & .03221 & 74.50 & .03494 & 74.10 & .03018 & 73.31 \\
$\sigma^{2} \mathrm{v}$ & .00956 & 22.11 & .01108 & 23.50 & .00909 & 22.08 \\
$\boldsymbol{\sigma}^{2} \mathrm{w} / \boldsymbol{\sigma}^{2} \mathbf{u}$ & 22.06 & & 30.92 & & 15.88 & \\
$\sigma^{2} \mathrm{v} / \boldsymbol{\sigma}^{2} \mathbf{u}$ & 6.54 & & 9.80 & & 4.78 & \\
\hline
\end{tabular}


For the estimated models the cross-section error ranges from 73.3 percent to 74.5 percent of the total error. Given this imbalance of the total error accounted for by the cross-sectional portion it is likely that the inclusion of a cross-sectional variable would improve the model. These missing variables might include an amenity or pollution index although to the degree to which distance, pollution and/or amenities are correlated this effect may be captured by the distance variable. ${ }^{8}$ Differences in the housing characteristics in each town could also explain a portion of the crosssectional variation but historical statistics on these variables are unavailable for the area under analysis. Fortunately, given the predictive power of the models it is likely that the inclusion of these variables would not add greatly to prediction. That is, in spite of the imbalance of the errors the total error is not large.

Contrary to expectations based upon the claims of TDR proponents, the TDR coefficient remained negative and significant throughout. Thus, it would seem that for this sample the existence of TDR has significantly reduced the growth of assessed value. To the degree that the growth of assessed value is related to the rate of development it would seem that TDR has had a significant negative effect upon the development rate. It would further seem that there is little support for the belief that growth within a community will be merely redistributed.

Density, density-squared, the construction price level and its lagged value are all estimated to be significantly different from zero with signs as expected. The finding that the negative effect of the price level is greater than the positive effect of lagged prices for all three models is consistent with the observed reduction in construction starts nationally, and especially in the Northeast, which began in the early 1970's.

While the overall effect of construction prices on the rate of change of assessed value is negative the reverse is true for the density variable. In all models density more than offsets the negative effect of density-squared. This is not surprising given that the average 1979 density in Bucks county is a relatively low 2,650 persons per square mile. ${ }^{9}$ Density values per square mile at the root values of the quadratic are presented in Table 3 (negative values are omitted).

Given the 1979 densities no towns were even half of Model I's required upper bound. For both models II and III, however, one town did surpass

\section{TABLE 3}

Density and Elasticity at Quadratic Root Values

\begin{tabular}{rrrrrr}
\hline \multicolumn{2}{c}{ Model I } & \multicolumn{2}{c}{ Model II } & \multicolumn{2}{c}{ Model III } \\
Value & Elasticity & At Root & Value & Elasticity & Elasticity \\
36,824 & -1.3126 & 14,912 & At Root & Value & At Root \\
8,112 & .9405 & & .7938 & 12,341 & .9149 \\
& & & & & \\
\hline
\end{tabular}


the required value. The total population of this town grew at a 2.6 percent rate in the period from 1963 to 1979 while the rate of growth of assessed value was 13.4 percent. The comparable countywide statistics were 90.2 percent for population and 39.8 percent for assessed value.

Income proved to be the most significant explanatory variable. It is much more interesting to note, however, that the third model, which included both income and distance, resulted in an estimated nonsignificant but positive distance variable. The correlation coefficient between these variables was -0.13 indicating that serious multicollinearity could not be considered the cause of the sign change and reduced significance of the distance variable.

Though the sign of the distance variable in Model III is unusual the result is not inexplicable. A modified form of the Muth-Alonso model is able to handle a positive distance relationship without difficulty (Weiand and Muth, 1972). In this modified form the rent-distance gradient is shown to depend on two quantities: one negative, the transport cost; and one positive, an amenity index which increases with distance from the CBD. If the amenity index outweighs that of transport costs a positive distance coefficient will result. Further, although the estimated distance coefficient is positive it is not significantly so, a negative value is not precluded.

\section{CONCLUSIONS}

Proponents of TDR schemes have advanced a number of claims regarding their virtues (Rose, 1979). These claims all rely upon the assumption that the areas affected by the TDR scheme will continue to grow at the preTDR rate but that growth will be directed in accordance with public goals. Implicitly assuming that the post-TDR redistributions are costless proponents arrive at the conclusion that the plans yeild Pareto efficiencies. Thus they claim that the plans treat landowners equitably. However, contrary to the claims of proponents TDR schemes result in a negative relationship for the TDR-affected area.

The results of this study suggest that while TDR schemes are an effective method of controlling growth they do not simply redistribute growth. In light of this evidence the equity claim must be re-examined.

\section{FOOTNOTES}

\footnotetext{
${ }^{1}$ Bucks County, Pennsylvania.

${ }^{2}$ Collier County, Florida.

${ }^{3}$ Chicago, Illinois and New York City.

${ }^{4}$ An excellent survey of this is in Wolf (1981).

${ }^{5}$ Peter Wolf describes the so-called replacement cost method as follows, "present replacement costs are estimated and deductions of value assigned for physical depreciation (are made), then the presumed (current) value of land is added."

${ }^{6}$ Upper Makefield and Buckingham Townships. Although two observations per year for TDR may seem
}

small it is unlikely that TDR plans will be used in such proximity in other locations. This proximity coupled with the virtually identical legislation make Bucks County the best sample currently available. Regressions yielded similar results when limited to Central Bucks County containing only 26 towns but this division seemed arbitrary.

${ }^{7}$ Sources and calculations are listed in Appendix A.

${ }^{8} \mathrm{~A}$ number of suggested variables appear in Berry and Bednarz (1975).

${ }^{9}$ The corresponding figure for neighboring Philadelphia was over 17,000 persons per square mile. 


\section{REFERENCES}

1. Amemiya, Takeshi 1971. "The Estimation of Variances in a Variance Components Model." International Economic Review (February): 1-13.

2. Babcock, Richard F. 1969. The Zoning Game. (Madison: University of Wisconsin Press.

3. Balestra, Pietro and Nerlove, Marc 1966. "Pooling Cross-section and Time-series Data in the Estimation of a Dynamic Model: The Demand for Natural Gas." Econometrica (July):585-612.

4. Barrese, James T. 1983. "Efficiency and Equity Considerations in the Operation of Transfer of Development Rights Plans." Land Economics (May):235-41.

5. Berry, Brian and Bednarz, Robert 1975. "A Hedonic Model of Prices and Assessments for Single Family Homes: Does the Assessor Follow the Market or the Market Follow the Assessor?" Land Economics (February):21-40.

6. Costonis, John J. 1974. Space Adrift: Landmark Preservation and the Marketplace. (Urbana: University of Illinois Press).

7. Hamilton, Bruce W. 1978. "Zoning and the Exercise of Monopoly Power." Journal of Urban Economics (January):116-130.

8. Mills, Edwin 1969. "The Value of Urban Land," in Perloff, Harvey (ed). The Quality of the Urban Envi- ronment. (Washington, D.C.: Resources for the Future).

9. Muth, Richard 1969. Cities and Housing. (Chicago: University of Chicago Press).

10. Nerlove, Marc 1971. "Further Evidence on the Estimation of Dynamic Relations from a Time-series of Cross-sections." Econometrica 39(March):359-82.

11. Ohls, James C., Weisburg, Richard C, and White, Michelle J. 1974. "The Effect of Zoning on Land Value." Journal of Urban Economics (October):428444.

12. Rose, Jerome G., ed., 1975. The Transfer of Development Rights: A New Technique of Land Use Regulation. (New Brunswick, N.J.: Center for Urban Policy Research).

13. Rose, Jerome G., ed., 1979. Legal Foundations of Land Use Planning. (New Brunswick, N.J.: Center for Urban Policy Research).

14. Searle, S.R. 1971. "Topics in Variance Components Estimation." Biometrics (January): 1-76.

15. Weiand, Kenneth F. and Muth, Richard F. 1972. "A Note on the Variation of Land Values with Distance from the CBD in St. Louis." Journal of Regional Science (December):469-473.

16. Wolf, Peter 1981. Land in America: Its Value, Use and Control. (New York: Pantheon Books).

\section{APPENDIX A: DATA SOURCES}

1. TDR. Bucks County Planning Board, Doylestown, Pennsylvania.

2. Distance. Estimated from U.S. Geological Survey maps.

3. Density. Formula used: Town population divided by Town land area.

4. Population. U.S. Bureau of the Census, Census of Population: 1970, Vol. 1, Characteristics of the Population., Part 40, Pennsylvania-Sections 1 \& 2. Washington, D.C.: U.S. Government Printing Office. Also, Historical Statistics of the United States.

5. Area. U.S. Census Bureau, Area Measurement
Reports, 1960. Washington, D.C.: U.S. Government Printing Office, 1970.

6. Price Level. Producer Price Index, Historical Statistics of the United States. U.S. Department of Commerce. Table n.792.

7. Income. Estimated Per Capita Money. P-25 Series, U.S. Department of Commerce, Bureau of the Census. No. 676-699 (1977) and no. 771 (1979).

8. Assessed Value. Gathered from the "Valuation and Assessment Roll," Doylestown County Courthouse, Bucks County, Pennsylvania. 